\title{
EXISTE UMA GENEALOGIA POSSÍVEL NA PSICANÁLISE?
}

Leonardo Danziato

Psicólogo,

psicanalista,

mestre e doutor em Sociologia pela Universidade Federal do Ceará (UFC). Professor titular da Universidade de RESUMO: A partir da noção de "gozo", aqui considerada como um conceito e uma dimensão do campo da psicanálise, interroga-se a lógica estrutural deste campo, sugerindo-se a possibilidade de introduzir uma leitura também genealógica sobre o gozo e o corpo. Fortaleza (Unifor). Articulam-se algumas proposições psicanalíticas com uma genealogia foucaultiana, sugerindo, por fim, alguns momentos da obra de Lacan, em que se poderiam vislumbrar considerações genealógicas na construção dos conceitos psicanalíticos.

Palavras-chave: Genealogia, gozo, corpo, história, estrutura.

ABSTRACT: Is there a possible genealogy in psychoanalysis? Based on the idea of jouisance, here viewed both as a concept and as a dimension in the field of psychoanalysis, the author examines the structural logic of this field, suggesting the possibility of introducing an also genealogical reading about jouisance and the body. Some psychoanalytical propositions are linked to Foucault's genealogy, eventually suggesting that genealogical considerations in the construction of psychoanalytical concepts could be discerned at some moments in the work of Lacan.

Keywords: Genealogy, jouisance, body, history, structure. 


\section{PSICANÁLISE E HISTÓRIA}

O gozo pode ser situado como uma segunda grande descoberta de Freud. Como sugere Lacan (1992, p.73), a descoberta primeira de um saber inconsciente articulado o levou a uma segunda, o "além do princípio do prazer" (FREUD, 1920/1976), que se apresentou clinicamente como fenômenos da ordem da repetição e do gozo.

Foi necessário esperarmos por Lacan para retirar dessa descoberta suas consequências as mais radicais. Ele não só nomeou o "além do princípio do prazer" com um termo mais adequado — o gozo — como, a partir daí, pôde realizar um segundo "retorno a Freud”, como sugere Braunstein (1990, p.15).

O gozo parece funcionar como um segundo "ponto do basteamento", que produz um retorno a posteriori a questões anteriores, renovando-as. Por isso, Brausntein faz uma convocação a todos os psicanalistas ao afirmar que "o gozo obriga a reescrever e a refazer a psicanálise” (BRAUNSTEIN, 1990, p.43).

Na condição desse elemento inefável, esse real incalculável, o gozo pode possibilitar uma via para redimensionar a posição política e genealógica da psicanálise. Pois, para além do seu "logocentrismo", 2 e do imperialismo do Édipo, é possível considerá-lo como esse elemento “estranho” (Unheimlich), que recoloca para a psicanálise a questão ética e política da gestão cultural das singularidades, do governo de si e do outro.

É como uma resposta a essa convocação — essa de renovar a psicanálise constantemente, que acompanha todo psicanalista — que proponho uma leitura peculiar da dimensão do gozo no campo da psicanálise, o que determina a consideração de uma localização incomum deste "campo do humano" (LACAN, 1992). Mesmo não desconsiderando sua lógica estrutural — lógica singular ao campo psicanalítico — achamos possível localizá-lo numa condição históricogenealógica na qual se encena.

Trata-se de articular psicanálise e história? Não haveria aí uma polêmica delicada, uma armadilha comprometedora? Não se deveria considerar que a lógica estrutural promovida por Freud e Lacan ultrapassa a história, a hermenêutica e a

\footnotetext{
1 “Ponto de basteamento", ou "Ponto de basta", ou ainda, "Ponto de estofo", são as várias traduções possíveis para uma proposição contida no que Lacan denominou de "Grafo do desejo", em seu escrito "A subversão do sujeito e dialética do desejo no inconsciente freudiano" (1998a). Trata-se de um ponto de retorno a posteriori que permite os efeitos de significação.

${ }^{2}$ Há uma crítica pertinente dirigida à psicanálise, formulada por autores como Derrida (2002), Foucault (1999), Deleuze e Guattari (1976), que diz respeito a sua insistência em reposicionar o real no campo da significação e do saber, seja na mitologia edipiana, seja na lógica do significante. Mais do que um 'equívoco' da psicanálise, os autores demonstram que esse é um traço genealógico do mundo ocidental. É lógico que podemos relativizar essa crítica a partir da dimensão do real e do gozo — é o que estamos buscando — mas isso não retira a pertinência da sinalização para o campo psicanalítico.
} 
fenomenologia? As considerações que apresentarei não se fazem sem o suporte de uma leitura histórica e genealógica de uma série de proposições, inclusive psicanalíticas. Tal procedimento coloca este trabalho diante de um risco: historicizar determinadas proposições que do ponto de vista psicanalítico escapam a uma determinação histórica. Estaria me contrapondo a uma condição estrutural do sujeito, condição esta afirmada pelo campo psicanalítico?

Acredito que é possível pensar essa lógica estrutural e suas afetações diante de transformações e deslocamentos genealógicos, já que a dimensão estrutural em psicanálise não se adequa a uma naturalidade. Suponho que é pela via do gozo que é possível estabelecer essa leitura, sem desconsiderar a singularidade estrutural da lógica psicanalítica, mas também sem desconhecer seus limites e deficiências no que tange a uma localização genealógica dos seus conceitos. Por isso, a pretensão em situar genealogicamente a dimensão do gozo exige uma leitura de uma regulamentação cultural de uma economia de gozo, e seus deslocamentos promovidos pelas transformações genealógicas do mundo moderno e contemporâneo.

Não posso desconsiderar, contudo, que Lacan rejeita explicitamente certa concepção de história. No seminário Encore, diz ter as melhores razões para detestar a história, já que "a história é precisamente feita para nos dar a ideia de que ela tem um sentido qualquer” (LACAN, 1985, p.63).

Sendo um seminário sobre o gozo — en corps — ${ }^{3}$ Lacan não poderia tomar outra posição, já que o gozo implica exatamente numa exclusão do sentido na história, um furo no saber, um limite entre o real e o simbólico. Para Lacan, a história funcionaria como um equívoco a posteriori, de onde faria remeter um exagero de sentido, encobrindo, assim, a experiência com o real. Como esclarece Zizek, para Lacan a história seria sempre ideológica, pois não passaria de um basteamento que introduz a ordem de modo retroativo (ZIZEK, 1991, p.198). Ela incorreria na fixação de um ponto de significação, produzindo um "ponto de saturação significativa que fecha o campo de significação" (idem, p.200).

O objetivo da história seria, por meio de um "passe de mágica”, fazer de conta que controla o núcleo do real que determina a impossibilidade de totalização (idem, p.200/201).

Essa história decerto estaria em desacordo com minhas proposições, já que tento acompanhar a ideia freudo-lacaniana de uma impossibilidade radical de completude, de gozo, ou mesmo de significação. Seguimos a ideia, tal como formulada por Zizek, de que "o processo da historicização comporta um lugar vazio, um núcleo a-histórico em torno do qual se articula a rede simbólica”

\footnotetext{
3 Este seminário está traduzido como "Mais, ainda" (1985). O titulo em francês Encore faz uma homofonia com en corps (no corpo). Trata-se de uma referência ao gozo do corpo, ao mesmo tempo que também se refere a uma fala das mulheres francesas durante a relação sexual.
} 
(idem, p.178). A história comporta um lugar vazio da coisa (das Ding), que funciona mesmo como o motor da história; há um núcleo a-histórico na história que permite a historicização e a simbolização. Isto não é outra coisa senão a dimensão do Real, que Lacan deslocou, no percurso de sua obra, para o centro da estrutura. O real é o motor e a causa da história.

Pensar a história a partir daí, muda completamente as possibilidades de introdução desse vetor no campo da psicanálise, pois nos permite considerar o que há de mais radical neste campo, sem incorrer numa ideologização, ou numa universalização, ou numa "historicização apressada" (idem, p.15).

Podemos, então, acompanhando Juranville, objetar as restrições lacanianas, e pensar a história não necessariamente como um fechamento das possibilidades de significação, mas pelo contrário, como uma "experiência do real que abre os possíveis” (JURANVILLE, 1995, p.385). Para Juranville, a emergência do mundo histórico acarreta uma ruptura com o mundo tradicional, de maneira que,

“estabelece-se um mundo diferente onde a indagação pode ser colocada, onde o pensamento absoluto é possível. Mundo histórico, ordenado pelo político, para que se mantenha a possibilidade da indagação. Mundo onde o sagrado se apaga. É nesse mundo histórico que o pensamento absoluto se enuncia através do discurso filosófico." (idem, p.384)

A ruptura que a história estabelece com o mundo tradicional não só permite o pensamento filosófico, como também a própria ideia de inconsciente, ou mesmo o discurso do analista, como sugere Lacan, que nem sempre esteve aí (LACAN, 1992). Isso constitui uma abertura para a dimensão do real, por mais que possa também produzir algumas suturas simbólicas e imaginárias.

Deste ponto de vista, entendo que é possível uma referência à história, como tantas que Lacan fez — às quais retornarei mais tarde — mas de maneira que se a considere em sua topologia “tórica”. Lacan utiliza-se de uma figura topológica que lhe é bastante cara, o "toro”. Trata-se de uma figura em forma de câmara de ar, e que por isso contém dois vazios: um vazio interno, por onde passa o ar, e um outro, que as bordas da câmara desenham, e que curiosamente, não podemos dizer com certeza se é interno, ou externo; ele partilha de uma "extimidade", 4 como sugere Lacan. Utiliza-se dessa figura topológica para dizer das relações entre o desejo e a demanda do sujeito com o Outro(A).

Podemos olhar e fazer uma história, portanto, cuja topologia seja "his-tórica"; considerando aí esse elemento de real tão caro à obra de Lacan. É possível pensar

\footnotetext{
4 Neologismo utilizado por Lacan para dizer dessa 'intimidade estranha' que o vazio e o buraco apresentam para o sujeito. Ver Lacan, 2002.
} 
que a história gira em torno desse real do sexo e da morte, e que a cultura, a política, os discursos de uma maneira geral buscam circundar esse vazio, produzindo, assim, formas históricas de gerenciamento simbólico e imaginário desse núcleo a-histórico do real.

Assim, introduzir uma dimensão histórica na leitura das condições culturais, discursivas, topológicas e políticas de gestão do gozo, não se contrapõe necessariamente a essa topologia e a essa "política” psicanalítica, que postula o real no centro da estrutura. Pelo contrário, possibilita pensar como se exerce uma “colonização imaginária” (LACAN, 1988, p.125) desse real da coisa.

Concordo, portanto, com Bursztein ao sugerir que a psicanálise aplicada à história — nesta perspectiva — não sai de seu campo de competência (BURSZTEIN, 1998, p.13). Neste sentido deve-se entender a história como o "campo onde se desenrola o gozo humano” (idem, p.20). E concluindo diz o autor:

"Os diferentes discursos que estruturam cada forma de civilização devem ser concebidos como modos de aparelhamento e de produção do gozo que se produz e se reproduz na História. Nessa ótica psicanalítica, cada civilização será caracterizada pela maneira como combina em si esses diferentes aparelhos de gozo." (idem, p.20)

Na construção da sua topologia dos quatro discursos, além de uma leitura primorosa dos deslocamentos políticos e discursivos da modernidade, Lacan nos fornece uma série de instrumentos que possibilitam considerar o real na história.

Podemos dizer que sua ideia fundamental sugere a existência de discursos que funcionam como lógicas inconscientes que organizam a distribuição e o controle do gozo para o sujeito, mas que não deixam de se apresentar numa topologia cultural e genealógica. Seu seminário “O avesso da psicanálise” (1992) está recheado de referências históricas e genealógicas. Como afirma Burzstein, “essas quatro lógicas [e acrescentaríamos uma quinta, a do capitalista] são articuladas e formam uma espécie de 'trama' inconsciente que condiciona a produção e a reprodução de toda cultura” (BURZSTEIN , 1998, p.22).

Considerando que os discursos giram em torno do real e do gozo, podemos pensar que a lógica discursiva dominante numa determinada época estabelece as relações topológicas entre os elementos significantes e os lugares no discurso em torno de uma grafia possível, ou mesmo autorizada, desse real; e que as relações do sujeito com o outro, o saber, a verdade e o gozo funcionam a partir de uma forma topológica específica, dependendo de como a "dominância de um discurso" trate o real do sexo e da morte, portanto, o real do corpo. A topologia discursiva dominante em determinada época é o que organiza as grafias possíveis do sujeito em torno do real, estabelecendo as relações topológicas entre o sujeito e o outro, entre o saber e a verdade, e seus efeitos de gozo. 
É possível afirmar, portanto, que a topologia dos discursos em Lacan indica uma proposição axiomática: o real anima a história. Os movimentos históricos são fundamentados pelas formas discursivas de determinada época. Essas formas discursivas, por sua vez, são produzidas e suscitadas pela maneira como naquele momento é possível tratar o real da verdade e do corpo. As condições de possibilidade e de pensabilidade de uma época são determinadas pela localização que se faz do real nos discursos.

Se quisermos saber como se pensa, se fala, se vive, se subjetiviza, enfim, como se goza em um determinado tempo histórico, devemos pesquisar, estudar, dentre as formações discursivas de uma época, a maneira como tratam o real e sua especial relação com o saber e a verdade. Ou seja: é possível pensar que historicamente há uma dominância de uma topologia discursiva, a qual possibilita uma "economia dos discursos" (FOUCAULT, 1999b) e uma "política da verdade" (idem), mas essa economia e essa política tratam fundamentalmente de uma economia política de gozo.

O que estou propondo é que, se os movimentos históricos são caracterizados pelas formas discursivas de determinada época, essas formas discursivas, por sua vez, são produzidas e suscitadas pela maneira como naquele momento é possível tratar o real. Cada época constitui seus discursos e práticas características, em função da forma como pode lidar com o real. Os discursos ilustram a maneira como determinada época trata o real do corpo, portanto, o real do sexo e da morte. E a movimentação histórica, seus deslocamentos e rupturas implicam uma modificação, um deslocamento discursivo na forma de tratá-los.

É essa leitura histórico-genealógica que estou propondo como uma leitura possível para a topologia lacaniana dos quatro discursos; ou seja, os discursos como dispositivos topológicos que tentam dizer das diversas formas como histórica e genealogicamente se trata o real do corpo; e que em cada época podemos observar a dominância de um desses discursos, já que ele ganha um poder de significação da verdade, estabelecendo um lugar e uma relação entre o saber, a verdade e o gozo.

A partir daí, creio ser possível conduzir essa leitura para uma genealogia do gozo, o que nos leva a uma proximidade com a obra de Foucault, que já nos indicou as formas discursivas históricas dominantes, e como se tratou o corpo e o sexo na modernidade. Eis o ponto no qual se pode pensar a correlação discursiva entre o saber, a verdade, o corpo e o gozo na modernidade e na pósmodernidade; condição política da verdade já estabelecida por Foucault, que me parece importante considerar.

Essa posição me leva a algumas considerações cruciais: a de pensar a cultura como gerenciadora do mal-estar e do gozo, através dos seus ideais embutidos numa topologia discursiva que busca grafar o real do corpo - o que não nos 
distancia do texto freudiano sobre "O mal-estar na cultura" (1930/1974); sendo que essa topologia se organiza em referência a determinadas configurações diagramáticas (FOUCAULT, 1977), políticas que estabelecem uma relação específica, historicamente determinada com o saber, a verdade, o gozo e suas impossibilidades. É preciso considerar, então, como cada configuração discursivo-diagramática apresenta um lugar para o real e para o impossível.

\section{A GENEALOGIA E O CORPO}

As obras de Lacan e Foucault parecem correr de forma paralela em suas preocupações com a dimensão do real, mesmo que o olhar e os objetivos práticos sejam bem diferentes. Dizemos isso porque os temas com os quais trabalham giram em torno do real do sexo, da morte, da loucura, do corpo. É óbvio que não se trata do mesmo real em ambos os autores, mas sem dúvida há uma mobilização de ambos pelos "eventos do real", mesmo que determinando abordagens diferentes na leitura de uma condição discursiva e política do corpo. Existem pontos em comum, contudo, que nos indicam uma possibilidade de interlocução.

O corpo com um espaço de escritura ${ }^{5}$ é uma delas. Quando Foucault define a genealogia como um "método" ele a ampara na sua relação com o corpo, retirando-o de sua naturalidade biológica. É a própria noção de corpo, sua naturalidade, sua essência e mesmo a sua biologia que ficam interrogados por um "olhar" desnaturalizante da pesquisa genealógica. É o corpo como um alvo e operador político que vai determinar um desvio do olhar na obra de Foucault para as práticas concretas e seus efeitos "materiais". Com isso ele busca conjurar a "quimera da origem" (FOUCAULT, 1979, p.19), da identidade e da profundidade.

A genealogia, portanto, é um método que se opõe a uma concepção tradicional da história, já que busca uma proveniência das estratégias de dominação, a política da verdade, e não os significados profundos ou essenciais no progresso da história. Não há sujeito da história. Como esclarecem Dreyfus e Rabinow, os significados devem ser procurados "nas práticas superficiais e não nas profundidades misteriosas” (DREYFUS e RABINOW, 1995, p.119).

Como se pode observar, há uma proximidade entre as concepções de história de Foucault e Lacan, já que em ambas encontramos uma destituição dos significados profundos, ou do sentido da história. Para ambos, não há sentido, não há sujeito da história, já que ela avança na lida com o real e o corpo.

O trabalho genealógico, portanto, implica considerar o corpo como o efeito de uma escritura e de produção: "a genealogia é um diagnóstico que se concen-

5 O termo 'escritura' se refere à ideia de Lacan de que o simbólico (a linguagem) lida com o real fazendo escrituras que, mais do que uma escrita, implica uma borda com o significante (LACAN, 2002). 
tra nas relações de poder, saber e corpo na sociedade moderna” (idem, p.117) Trata-se de um procedimento que Dreyfus e Rabinow chamam de o "empreendimento de Foucault", ou seja, o de tentar esclarecer "como o corpo se tornou o componente essencial para a operação das relações de poder na sociedade moderna" (idem, p.125).

Considero importantíssimo esse esclarecimento sobre a radicalidade da crítica que a posição do genealogista comporta, pois é a partir dela que poderei inserir uma ideia de corpo e do gozo como um alvo e objeto da política.

Esse olhar possibilita retornar criticamente a algumas concepções psicanalíticas de forma a conjurar não só a quimera da origem, mas também da estrutura. A genealogia permite uma redução histórica da origem, ou mesmo, uma redução ao real da história, por meio de uma pesquisa da "proveniência" (FOUCAULT, 1979, p.20), de maneira a descobrir "que na raiz daquilo que nós conhecemos e daquilo que nós somos — não existem a verdade e o ser, mas a exterioridade do acidente" (idem, p.21); um encontro com o real — tiqué (LACAN, 1998b).

Trata-se de uma convocação para "historicizar” os conceitos, mas também para "histericizá-los" (LACAN, 2002), trazendo-os para sua ancoragem no real do corpo, este "ponto de articulação entre o corpo e a história” (FOUCAULT, 1979, p.22).

Neste sentido não me parece haver um equívoco em buscar um entendimento histórico daquilo que se apresenta como estrutural, nem mesmo para a psicanálise, pois é possível encontrar na obra de Lacan uma preocupação em situar a "emergência” (idem, p.23) dos conceitos e da própria psicanálise em suas condições relativas ao tratamento discursivo dado ao real numa determinada época (DANZIATO, 2006).

Obviamente que isso envolve outra concepção de história, tal como nos referimos antes, que não parta das origens ou do fornecimento de um "sentido qualquer", mas uma história que possa se libertar da "história supra-histórica" (FOUCAULT, 1979, p.33). Uma história que segundo Foucault possa comportar três usos:

Um "uso paródico e destruidor da realidade" (idem, p.33);

Uma "dissociação sistemática de nossa identidade" (idem, p.34);

Um “sacrifício do sujeito do conhecimento” (idem, p.35).

Não é difícil concluir que a dimensão do gozo com seus efeitos de desconstrução, seus efeitos de real, possibilita uma leitura dessa ordem, já que guarda em sua "estrutura” o vazio, um buraco, que não comporta nem a identidade, nem a origem, nem a verdade, mas se estabelece nessa tela de escritura que é o corpo. 
É preciso, pois, introduzir uma materialidade do corpo e do gozo nesse drama político-subjetivante, tentando compreender como os poderes incidem e afetam os sujeitos em suas "economias subjetivas de gozo" (LACAN, 1998), seja na forma das interdições — que não são as únicas — seja por meio de "modos de subjetivação" e de "sujeição" (FOUCAULT, 1984), através de "proposições" discursivas de gozo, isto é, na produção e no oferecimento dos saberes — saber-poder — para se subjetivar, assim como de objetos para gozar, no consumo e usufruto capitalista.

O corpo, tal como concebido por Foucault como o espaço de incidência política por excelência nos processos genealógicos fundados na modernidade, possibilita-nos uma indagação acerca das "políticas do corpo" (FOUCAULT, 1977). Neste mesmo sentido, o corpo, tal como tratado pela psicanálise e muito especialmente por Lacan, como um espaço não apenas físico-fisiológico, mas como fazendo parte das dimensões do real, do simbólico e do imaginário, como espaço de uma "escritura" subjetiva, ética e política, abre a possibilidade de uma leitura genealógica da dimensão do gozo.

Esse olhar genealógico dirigido ao corpo possibilita pensar que uma "economia de gozo" (LACAN, 2004) não se situa somente num espaço individual e fantasmático, mas a partir de uma relação topológica do sujeito com o outro do laço social (LACAN, 1992), no qual se encena uma constituição moral e/ ou ética sugerida e permitida pela cultura. É possível pensar, a partir de Lacan, que há uma homologia discursiva e ética entre uma "economia subjetiva" - de gozo - e uma "economia política" que sugere e controla o gozo dos "bens" (LACAN, 1988), dos "objetos", das "mercadorias", e mesmo um "gozo do corpo". A economia subjetiva do sujeito implica, portanto, em sua constituição, uma economia política do gozo, que se encena nas estruturas discursivas de determinada sociedade. Acompanha, pois, os deslocamentos históricos, discursivos, políticos e econômicos, já que o que se encena aí é uma história política e ética da verdade, do saber e do corpo.

Concordando com Foucault que o poder é positivo e produz saberes, discursos e uma economia política da verdade, e considerando o saber como um "meio de gozo" (LACAN, 1992), como afirma Lacan, posso sugerir que o poder, em suas incidências sobre as subjetividades, também produz formas de gozo, através do controle e da produção de proposições discursivas historicamente determinadas. Cada época, cada "situação estratégica" de determinada sociedade, sugere, propõe, impõe sutilmente, através de determinados "dispositivos" (FOUCAULT, 1988) e diagramações discursivas, formas muito próprias de gozo, que incidem subjetivamente sobre os corpos e as subjetividades, mas que guardam uma relação discursiva com a história do seu momento político e econômico.

Essa ideia possibilita reafirmar que em cada época, em cada cultura encontramos formas "discursivas dominantes" — apesar de não exclusivas — ou mesmo 
uma diagramação política peculiar, que revela as formas como a cultura, naquele momento, gerencia seus poderes por meio de proposições e interdições, produzindo, segundo Foucault, uma "economia política da verdade" (FOUCAULT, 1999b). Podemos dizer, nesta mesma direção e seguindo as proposições de Lacan, que a cultura, ao produzir uma economia política da verdade, produz também uma "economia política do gozo". A cultura com seus discursos — tais como a política, a educação, a moral, a ética, a ciência, a religião, ou mesmo a psicanálise - busca produzir, conduzir, grafar e interditar as formas de gozo, por meio de uma "moral do poder" (LACAN, 1988), de uma ética, ou de uma “dietética” no "uso dos prazeres" (FOUCAULT, 1984).

Dizendo de maneira mais direta, a partir da concepção de discurso em Lacan: os discursos são formas de barrar o gozo, mas ao mesmo tempo "meios de gozo" (LACAN, 1992) que são sugeridos pela cultura; são formações discursivas que buscam grafar, fazer borda no real implicado em toda relação do sujeito com a linguagem: o real do sexo e da morte.

O gozo aqui não é tomado simplesmente como uma "satisfação" mórbida, como podemos encontrar em Freud. Com Lacan, o gozo ganha o estatuto de “campo”, de um “campo de significação” (LACAN, 1985) do sujeito. Isso quer dizer que no decorrer da sua obra, a noção de gozo vai perdendo seu caráter meramente transgressivo, contrário à ética — tal como é tratado no seminário “A ética da psicanálise” — para alçar a condição de o "campo do humano" ou como solicita Lacan, o “campo lacaniano” (LACAN, 1992).

O gozo, portanto, é tratado por Lacan como o que habita o corpo humano, inevitavelmente. Não se cura do gozo, apenas se o administra na relação com o "outro"'6 e com a Lei — com L maiúsculo.

Isto significa que a relação da cultura, da Lei e fundamentalmente dos poderes modernos com o gozo, não é apenas de "proibição", mas também de "proposição" de "meios de gozo" autorizados. Esse entendimento da relação entre cultura, Lei e gozo pode servir para pensar não só as possibilidades de articulação entre a psicanálise e a política, mas também, e fundamentalmente, os efeitos dessas configurações diagramáticas na cultura sobre as subjetividades e sobre uma economia de gozo dos sujeitos.

Há, portanto, uma relação de imanência política e discursiva na produção das subjetividades, na incidência dos poderes sobre o corpo, na forma de controle e proposições de gozo. É necessário considerar o caráter histórico-político desta

\footnotetext{
${ }^{6}$ O lugar do 'outro' é fundamental na lógica teórica da obra lacaniana. Se em um momento esse outro foi tratado como um grande Outro (A), como um lugar conferido a uma dimensão simbólica, posteriormente esse outro ganha uma dimensão 'real'; ou seja, ele passa a ser pensado como o lugar de uma impossibilidade na relação com o 'outro'. Esse desenvolvimento perpassa toda a obra de Lacan. Ver Lacan, 1998b; 1988b; 2002 [1974/75], entre outros.
} 
correlação, já que a incidência do poder sobre o gozo — na produção mesmo das suas minúcias, como revelou Foucault (1988) — varia com a predominância discursiva de determinada época.

Para não incorrer numa história que fecha os sentidos, é necessário partir da ideia de que o real é o motor da história; o que me leva a considerar — quando se pesquisa - como determinada época trata discursivamente o real do sexo e da morte; como uma cultura capitaliza ou investe os restos das operações dimensionais entre o real, o simbólico e o imaginário (LACAN, 2002); restos que Lacan define como o "mais-de-gozar” (LACAN, 2004).

\section{PSICANÁLISE E MODERNIDADE}

A partir dessas proposições, e a título de conclusão, poderíamos interrogar genealogicamente a própria emergência da psicanálise na modernidade.

Poderia dizer que a modernidade, em seu "movimento pendular" (DANZIATO, 2006) apresenta um paradoxo: se ela produziu uma lógica tirânica da ordem e da disciplina — tal como demonstra Foucault (1977) — também permitiu uma descoberta do caos, dos buracos do absoluto, da impossibilidade da verdade, da desconstrução das totalidades. Ela introduz a “dimensão do real” no pensamento, que até então se encontrava velada por uma construção filosófica, ontológica e religiosa. A modernidade desvela o real, mesmo que sua política seja sempre a de buscar rechaçá-lo, por meio de um projeto político e discursivo totalizante. Sabemos que ela foi mesmo o efeito de todo esse processo de desconstrução do tradicional, operado pela ciência e pelo capitalismo. Por um lado, ela estabelece uma nova relação entre o saber e a verdade, revelando a dimensão real da verdade, retirando-a de uma lógica do absoluto, abrindo "buracos" na lógica discursiva - soberana - da cultura, e possibilitando, assim, a produção incessante de saberes. Ela destampa os buracos do real, produzindo "efeitos de sujeito" (LACAN, 2004, p.02); o aparecimento da ciência e da lógica permite ao sujeito uma escritura do real. Não é mais o Outro (A), primeiro lugar do "sujeito suposto saber", que escreve o real, mas o sujeito do conhecimento que se depara com a “crueza do real” e produz sua escritura. Essa crueza do real impõe uma incompletude dessa escritura, assim como uma entropia e uma impotência do saber diante da verdade. Essa constatação não é feita sem uma boa dose de angústia, que movimenta o sujeito numa tentativa incessante de recuperação desta perda entrópica, ou mesmo de recomposição de um todo da verdade — seja do ponto de vista político, ou mesmo epistemológico — através do seu "logocentrismo" característico (FOUCAULT, 1999c, p.22; DERRIDA, 2002).

Assim, a modernidade é, ao mesmo tempo, revolucionária e reativa, singular e universalizante, de vanguarda e reacionária. No mesmo ato em que produz um ordenamento e um disciplinamento político, permite em seu seio a construção 
de movimentos que lhes são "estranhos" (Unheimlich). No mesmo instante em que segrega seus estranhos também os constitui e os individualiza.

Foi esse movimento pendular, essa entropia, essa “divisão” inelutável que permitiu o surgimento de movimentos críticos: nas artes o modernismo; na política a denúncia marxista do capitalismo e dos "sintomas sociais"; 7 na filosofia a recuperação nietzschiana da dimensão do trágico e a crítica contundente de uma genealogia da moral; e por fim, a psicanálise e a introdução de categorias desorganizadoras da lógica da ordem, tais como o inconsciente, a pulsão e o gozo.

Esses movimentos podemos entendê-los, seguindo Lacan, como "sintomas" da modernidade e da civilização; sintoma aqui entendido em sua lógica freudiana, ou seja, como o que faz retornar uma verdade do sujeito. Por isso mesmo, Lacan afirma ser a psicanálise um "sintoma da civilização” (LACAN, 2004); ou seja, ela foi possibilitada por esse movimento entrópico da modernidade. Se há um retorno é porque em algum momento uma verdade fora rechaçada; ela revela uma verdade rechaçada pela modernidade: a verdade da “divisão do sujeito”, da impotência do saber, e da impossibilidade do gozo que daí resulta.

Eis uma singela leitura genealógica possível da emergência mesmo da psicanálise.

Recebido em 12/5/2008. Aprovado em 6/7/2008.

\footnotetext{
${ }^{7}$ Lacan dedica a Marx a descoberta da dinâmica do sintoma, constituindo assim uma revelação do "sintoma social" da modernidade. Ver Lacan, 2004 [1968/69] e Zizek, 1991.
} 


\section{REFERÊNCIAS}

BRAUNSTEIN, Nestor. (1990) Goce. México: Siglo Veintiuno.

BURSZTEIN, Jean-Gérard. (1998) Hitler, a tirania e a psicanálise. Ensaio sobre a destruição da civilização. Rio de Janeiro, Companhia de Freud.

DANZIATO, Leonardo. (2006) "O gozo e o poder — Sobre a dimensão genealógica do gozo”. Tese de Doutorado, Programa de Pós-graduação em Sociologia da Universidade Federal do Ceará (UFC).

DELEUZE, Giles e GUATTARI, Félix. (1976) O Anti-édipo. Capitalismo e esquizofrenia. Rio de Janeiro: Imago.

(1987) Foucault. Lisboa:Veja.

DERRIDA, Jacques. (2002) "Freud e a cena da escritura", in A escritura e a diferença. São Paulo: Perspectiva.

DREYFUS, Hubert e RABINOW, Paul. (1995) Michel Foucault. Uma trajetória filosófica: (Para além da hermenêutica e do estruturalismo). Rio de Janeiro: Forense Universitária.

FOUCAULT, Michel. (1977) Vigiar e punir. Petrópolis: Vozes. (1979) “Nietzsche, a genealogia e a história”, in Microfísica do poder. Rio de Janeiro: Graal.

(1984) A história da sexualidade II — O uso dos prazeres. Rio de Janeiro: Graal.

Graal.

(1988) A história da sexualidade I — A vontade de saber. Rio de Janeiro:

(1999) A verdade e as formas jurídicas. Rio de Janeiro: Nau Ed.

(1999b) A ordem do discurso. São Paulo: Loyola.

FREUD, Sigmund. (1976) Edição standard brasileira das obras completas de Sigmund Freud. Rio de Janeiro: Imago.

(1920/1976) “Além do princípio do prazer”, v.XVIII.

(1930/1974) “O mal-estar na cultura”, v.XXI.

JURANVILLE, Alain. (1995) Lacan e a filosofia. Rio de Janeiro: Jorge Zahar Ed.

LACAN, Jacques. (1985) Seminário, 20. Mais, ainda. Rio de Janeiro: Jorge Zahar.

(1985b) O eu na teoria de Freud e na técnica da psicanálise. Rio de Janeiro: Jorge Zahar.

. ([1959/60], 1988) A ética da psicanálise. Rio de Janeiro: Jorge Zahar.

(1988b) Os quatro conceitos fundamentais da psicanálise. Rio de Janeiro: Jorge Zahar.

. (1992) Seminário, 17. O avesso da psicanálise. Rio de Janeiro: Jorge Zahar.

(1998) “Subversão do sujeito e a dialética do desejo no inconsciente freudiano”, in Escritos, Rio de Janeiro, Jorge Zahar.

(1998b) "A instância da letra no inconsciente ou a razão desde Freud”, in Escritos, Rio de Janeiro, Jorge Zahar.

([1962], 1998c) “Kant com Sade”, in Escritos, Rio de Janeiro:

Jorge Zahar. 
([1974/75]/2002) Seminário, 22. RSI. (versión crítica) Publicación para Circulación interna de la Escuela Freudiana de Buenos Aires. (Mimeo)

. (2003) "Os complexos familiares na formação do indivíduo", in. Outros escritos. Rio de Janeiro: Jorge Zahar.

([1968/69], 2004) Seminário, 16. De um Outro ao outro. Publicação interna do Centro de Estudos Freudianos do Recife (CEF/Recife).

ZIZEK, S. (1991) O mais sublime dos histéricos. Hegel com Lacan. Rio de Janeiro: Jorge Zahar Ed.

Leonardo Danziato

leonardodanziato@unifor.br 